\title{
EXPLANATION OF TYPOGRAPHICAL AND REFERENCE SYSTEMS
}

The ancient manuscripts contain no headings, detailed numbering systems, or (in most cases) other marks to indicate divisions of text. The Coptic manuscripts also contain no punctuation corresponding to the kind that is used in English and Byzantine Greek.

\section{Boldface numbers in the text}

Boldface numbers which appear within the text indicate

(a) in works translated from the Coptic (Nag Hammadi MSS), manuscript page numbers according to the standard Leiden facsimile edition (e.g., 1 = MS page 1 );

(b) in works translated from the Greek or Latin, book, chapter, and section numbers (e.g., 1.24.1 = book 1 , chapter 24 , section 1 ) or, in Porphyry, chapter and section numbers.

\section{Marginal numbers}

Marginal numbers, set in small ordinary type, are the manuscript line numbers of the Coptic (Nag Hammadi) MS or, in Porph, the line numbers of the critical edition.

Dots $\bullet$ in the text are coordinated with these marginal numbers.

Line numbers are given only at the beginning of important sentences or phrases. Not every line of the Coptic manuscript is indicated in the text and margin.

The important sentences and phrases numbered in the English translation usually begin in the middle of a manuscript line of Coptic.

\section{Boldface headings in the text}

Boldface headings in the text have been added by the modern translator, as an aid to readers. They are not a part of the original text, and should be omitted when any part of this translation is quoted. 


\section{Italics}

Italics are used only in the text of BJn, EgG and ClExc. Their use is explained in the introductions to those three works, under "Text."

\section{Use of parentheses ( )}

Words in parentheses ( ) have been added by the modern translator, as an interpretive supplement implied by the text but not literally present within it. They may be retained whenever the translation is being quoted.

\section{Vertical lists in the text}

When a vertical list of items appears in the text (e.g., BJn 6:5f) this typographical arrangement has been added by the modern translator. Such vertical lists do not appear in the ancient manuscripts.

\section{Footnotes}

In each division of a text, footnotes are lettered serially. Footnotes for each page of text are printed at the bottom of the page.

\section{Marginal references}

Marginal references direct the reader's attention to other passages that can contribute immediately to an understanding of the text-sources of quotations and allusions; use of special terms, phrases, and images in related scriptures collected in the same part of The Gnostic Scriptures; and, rarely, comparable use of such a term, phrase, or image in an earlier body of scripture (see Table 1). Biblical parallels of mere terminology and imagery have almost never been noted. The references often occur in groups, all relating to one text line; in such cases, the position of the first reference indicates the line to which the whole group applies. If two groups of references have to be run together in one place, they are separated by a boldface reference to the new verse number. The symbol $\mathrm{f}$ ("and following line or lines") is usually omitted in marginal references.

Within a group of references, the order of items is:

1. Cross-references within the same work, in the appropriate order (these are not preceded by the abbreviated name of the work)

2. References to books of the Old and the New Testament

3. References to other works in The Gnostic Scriptures

Reference to works translated from the Coptic (Nag Hammadi MSS) takes the form of " $50: 3$," i.e., "page 50 , line 3 , of the manuscript."

\section{Symbols in Marginal References}

$\mathrm{f}$ "and following line (section) or lines (sections)." Either one or many lines (sections) may be represented by this symbol.

par. "and parallels in the other gospel(s)" 
+ " "principal reference." A marginal reference followed by this symbol (e.g., 9:9+) indicates a passage in whose margin further references to the same item are listed. References carrying this symbol may be especially useful to the interpreter.

\section{How to cite passages of this translation}

Full titles of works should be preferred to the abbreviations used in this book. Note the list of "Other Accepted Names for the Works in This Collection"; these names may be used if desired.

(a) For works translated from the Coptic (Nag Hammadi MSS and Codex Tchacos), cite the MS page number (boldface, in the text) and the line number preceding the citation (ordinary type, in the margin) joined by the symbol : (colon) and written solid. Unless the Coptic text has been consulted it is safest to write the symbol $\mathrm{f}$ ("and following line or lines") after the line number; the Coptic lines of text are short. For example, "Revelation of Adam 64:6f"; "Revelation of Adam 64:6-16f." It is unnecessary to specify the Nag Hammadi codex numbers except with The Secret Book According to John (Codex II) and The Egyptian Gospel (mostly Codex IV, but sometimes Codex III). For example, "The Secret Book According to John (Codex II) 1:5f"; "The Egyptian Gospel (Codex IV) 50:1-21f”; "The Egyptian Gospel (Codex III) 55:22f."

The Gospel According to Thomas should be cited by saying (logion) number, but The Gospel According to Philip by page and line.

(b) For works translated from the Greek or Latin, cite the full boldface number or numbers found in the text. For example, "St. Irenaeus of Lyon, Against Heresies 1.24.1"; "St. Epiphanius of Salamis, Against Heresies 39.1.4-39.3.5." Citations of the Hymn of the Pearl should specify "Greek," and for precision the traditional (Syriac) verse numbers printed in the margin may be added to the Greek paragraph numbers: "Hymn of the Pearl (Greek) 108-109, verses 11-19."

Editorial symbols representing the state of the ancient text

[of the] Missing because of physical damage (text conjecturally supplied by the modern editor)

[...] One or more words missing because of physical damage

$<$ not $>$ Inadvertently omitted by the ancient copyist (text conjecturally supplied by the modern editor)

$\langle\ldots\rangle$ One or more words inadvertently omitted by the ancient copyist

$\star * * \quad$ Passage omitted by the modern translator 
This page intentionally left blank 